\title{
Electroacupuncture enhance therapeutic efficacy of mesenchymal stem cells transplantation in rats with intracerebral hemorrhage
}

\section{Li Deng}

Southwest Medical University

Ling Zhou

Affiliated Hospital of Southwest Medical University

\section{Yan Zhu}

Southwest Medical University

Guangbi Fan

Southwest Medical University

\section{Huajun Tang}

Southwest Medical University

\section{Yujie Zheng}

Southwest Medical University

\section{Xiaoqing Gao}

Southwest Medical University

\section{Kan Guo}

Southwest Medical University

\section{Peng Zhou}

Wenzhou Medical University

Chaoxian Yang ( $\square$ chaoxian.yang@swmu.edu.cn )

Southwest Medical University https://orcid.org/0000-0002-7462-6423

\section{Research Article}

Keywords: Intracerebral hemorrhage, Mesenchymal stromal cells, Electroacupuncture, Cell transplantation

Posted Date: February 22nd, 2021

DOI: https://doi.org/10.21203/rs.3.rs-187284/v1

License: (c) (i) This work is licensed under a Creative Commons Attribution 4.0 International License.

Read Full License 
Version of Record: A version of this preprint was published at Stem Cell Reviews and Reports on March 4th, 2021. See the published version at https://doi.org/10.1007/s12015-021-10144-8. 


\section{Abstract \\ Background}

Previous studies have showed the beneficial effects of mesenchymal stem cells (MSCs) on experimental intracerebral hemorrhage (ICH) animal. Enhancement of the treatment efficacy of MSCs in ICH is essential, considering the diseases association with high rates of disability and mortality. Some auxiliary methods to enhance the beneficial efficacy of MSCs have been introduced. However, the effect of electroacupuncture (EA) on the therapeutic efficacy of MSCs transplantation in hemorrhagic stroke and its potential mechanism is not explored.

\section{Methods}

$\mathrm{ICH}$ rat models were established using collagenase and heparin. $48 \mathrm{~h}$ after ICH induction, the rats were randomly divided into model control (MC), MSCs transplantation (MSCs), EA stimulation (EA) and MSCs transplantation combined with EA stimulation (MSCs + EA) groups. We used mNSS test and gait analysis to assess neurological function of rats, and PET/CT to evaluate the volume of hemorrhage focus and level of glucose uptake. The concentrations of MDA, SOD, NSE, S100B and MBP in serum or plasma were examined with ELISA. Neural differentiation of MSCs, and the expressions of Bcl-2, Bax, Arg-1 and iNOS proteins around hematoma were detected by immunofluorescence and immunohistochemistry staining respectively. Western blot was carried out to analyze the expression levels of COX4, OGDH, PDH-E1a, Bcl2 and Bax proteins. TUNEL staining was used to estimate cell apoptosis and transmission electron microscopy (TEM) was used to observe the ultrastructure and number of mitochondria.

\section{Results}

Our data showed that EA promoted neuron-like differentiation of transplanted MSCs and the expressions of BDNF and NGF proteins in ICH rats. The score of mNSS and the gait analysis showed that the recovery of the neurological function in the MSCs + EA group was better than that in the MSCs and EA groups. EA improved the structures of brain tissue, and alleviated brain injury further after MSCs transplantation in $\mathrm{ICH}$ rats. When compared with the MSCs and EA groups, the level of glucose uptake and numbers of mitochondria and Arg-1 positive cells in MSCs + EA group increased significantly, but the numbers of apoptotic cells and iNOS positive cells and volume of hemorrhage focus reduced. The expressional levels of $\mathrm{COX} 4, \mathrm{OGDH}, \mathrm{PDH}-\mathrm{E} 1 \mathrm{a}$ and $\mathrm{Bcl}-2$ proteins increased, while the expressional levels of Bax protein decreased compared with those in the MSCs and EA groups.

\section{Conclusion}

Our results reveal that EA improve therapeutic efficacy of MSCs transplantation in ICH rats. 


\section{Introduction}

Stroke is a leading cause of death and related with long-term disability for survivors. Intracerebral hemorrhage (ICH) accounts for $10 \%$ to $15 \%$ of all strokes worldwide [1]. The management of ICH patients is generally limited to supportive care or removal of the hematoma; the efficacy of surgical evacuation of hematoma is variable and controversial [2]. After ICH occurs, the most significant pathological characteristic is the necrosis and apoptosis of a large number of nerve cells in lesions area, and loss of neurocytes is an important cause of disability $[3,4,5]$. Taking measures to reduce cell death or promote neurogenesis or replace the lost cells to improve brain structure are the basis for the recovery of motor, sensation and cognitive impairment in patients.

One major experimental strategy is to explore stem cells in improving neurological outcomes following $\mathrm{ICH}$. Previous investigations indicated that mesenchymal stem cells (MSCs) could differentiate into neurons across embryonic layer, and were regarded as an vital cell source for treatment of ICH [6,7]. In $\mathrm{ICH}$ animal model, MSCs transplantation promoted neurogenesis, functional recovery, and inhibit inflammation, and reduced hemorrhage volume and apoptosis $[8,9,10]$. However, single treatment is difficult to achieve the desired effect [11].

Electroacupuncture (EA), a novel and practical therapy based on acupuncture combining with modern electrotherapy can not only quantify stimulus parameters but also improve the curative effect and save manpower, has been clinically used to treat many nervous system diseases and is often used as a common complementary treatment for stroke [12,13]. EA stimulation can improve neurological deficit scores and brain injury which connected with a series of signal pathways and various other factors [14]. However, whether EA enhances the therapeutic efficacy of MSCs transplantation in ICH rats and its potential mechanism are not clear.

In this experiment, we observed the effects of EA stimulation and MSCs transplantation on behavioral dysfunction, brain structure, ultrastructure of mitochondria, brain injury, microglia, cell apoptosis, and apoptosis-related proteins in rats subjected to $\mathrm{ICH}$, and investigated whether EA improve therapeutic efficacy of MSCs transplantation in ICH rats.

\section{Materials And Methods}

\section{Animals}

All SPF Sprague-Dawley (SD) rats were obtained from the Laboratory Animal Center of Southwest Medical University. The rats were housed at room temperature $\left(23 \pm 2^{\circ} \mathrm{C}\right)$ in a $12 \mathrm{~h} / 12 \mathrm{~h}$ light/dark cycle with free access to food and water. Experiments abided by all relevant ethical regulations and were approved by the Animal Care and Use Committee at the Southwest Medical University. Animal studies were conducted on the adult SD rats with weighing 220-250 g and aged 8-10 weeks at experimental onset. The animals were separated into sham operation (SO) group and intracerebral hemorrhage (ICH) group, and the latter were randomly subdivided into model control (MC) group, MSCs transplantation 
(MSCs) group, EA stimulation(EA) group and MSCs transplantation combined with EA stimulation (MSCs+EA) group.

\section{ICH Rat Model}

$\mathrm{ICH}$ rat model was established as previously described by injecting collagenase and heparin [15]. Briefly, SD rat was anesthetized with $1 \%$ pentobarbital sodium $(40 \mathrm{mg} / \mathrm{kg})$ via intraperitoneal administration, and then placed on a stereotaxic apparatus (Benchmark, myNeurolab.com, USA). The scalp was incised longitudinally with $1 \mathrm{~cm}$ long in the midline, and a $1 \mathrm{~mm}$ burr hole was drilled on the right cranial bone at the point that was $0.2 \mathrm{~mm}$ anterior and $3 \mathrm{~mm}$ lateral to bregma. A sterile $5-\mu \mathrm{l}$ Hamilton syringe was then inserted into a point that was $6 \mathrm{~mm}$ ventral to the hole, and collagenase I $(2 \mu \mathrm{l}, 0.125 \mathrm{U} / \mu \mathrm{l}$, Sigma $)$ and heparin $(1 \mu \mathrm{l}, 2 \mathrm{U} / \mu \mathrm{l})$ were slowly injected into the right striatum of rat. Then the needle was removed, and the burr hole was sealed with bone wax and the scalp was sutured. After operation, all rats were allowed free access to food and water. For the SO group, the same procedure was carried out in the rats without injection of collagenase I and heparin.

\section{MSCs transplantation}

MSCs labelled with green fluorescent protein (GFP) (No. RASMX-01101, Cyagen Biosciences, Inc.

Suzhou, People's Republic of China; Inspection report seen in Supplementary Fig. 1) were recovered from liquid nitrogen and cultured by using alpha-minimum essential medium (a-MEM) (Hyclone) supplemented with $10 \%$ FBS (Hyclone), $100 \mathrm{U} / \mathrm{ml}$ penicillin and $100 \mathrm{mg} / \mathrm{ml}$ streptomycin (Gibco) in an incubator $\left(37^{\circ} \mathrm{C}, 5 \% \mathrm{CO}_{2}\right)$. When the $3-5$ generation of MSCs reached $80 \%$ confluence, the medium was substituted with preinduction solution comprised of a-MEM with $10 \%$ FBS and $1 \mathrm{mmol} / \mathrm{L} \beta$ mercaptoethanol ( $\beta-M E)$ for 24 hours, then with neuronal induction solution composed of a-MEM with $2 \%$ dimethylsulfoxide (DMSO), $1 \mathrm{mmol} / \mathrm{L} \beta-\mathrm{ME}$ and $1 \mu \mathrm{mol} / \mathrm{L}$ all-trans retinoic acid (RA) (Sigma) for 6 hours. The cells were collected and the cell concentration was adjusted to $2.5 \times 10^{7}$ cells $/ \mathrm{ml}$.

At 2 days following $\mathrm{ICH}$, rats of MSCs group and MSCs+EA group were anesthetized and placed on a stereotaxic apparatus again. The suture was disassembled and a sterile microsyringe with cell suspension was inserted into the point (coordinates: $0.2 \mathrm{~mm}$ anterior, $6 \mathrm{~mm}$ ventral, $3 \mathrm{~mm}$ lateral to the bregma) via the burr hole described above. Then, $5 \times 10^{5}$ cells in the total $20 \mu \mathrm{L}$ saline were slowly injected into the right striatum. After cell transplantation, the hole was filled with bone wax and the skin incision was sutured again. The animals survived for 2 weeks after cell implantation.

\section{EA stimulation}

The EA stimulation was performed according to the methodological standards as previously described [16] and the Baihui (GV20, located at the intersection of the median line of the head and the line connecting the apexes of the two auricles) and Dazhui (GV14, located at the posterior midline of the neck and between the spinous process of the seventh cervical vertebra and that of the first thoracic vertebra) acupoints were selected for EA stimulation. After cleaning the skin with alcohol swabs, the researcher 
inserted a sterile acupuncture needle into GV20 to the depths of $2 \mathrm{~mm}$ obliquely, and another needle into GV14 to the depths of $5 \mathrm{~mm}$ vertically to the skin. Then both of the needles were connected to EA stimulator (HM6805, People's Republic of China), and the rats were stimulated with continuous wave, intensity of $1 \mathrm{~mA}$, frequency of $3 \mathrm{~Hz}$ and stimulation duration of $10 \mathrm{~min}$. Rats of EA group and MSCs+EA group received EA stimulation once a day at 2 days following $\mathrm{ICH}$, and fourteen days in succession until the rats were sacrificed. Rats of MC group were not treated with EA and MSCs implantation.

\section{Neurological behavioral score}

At $2 \mathrm{~h}, 1 \mathrm{~d}, 2 \mathrm{~d}$ following the induction of ICH and $14 \mathrm{~d}$ after treatment, modified Neurological Severity Scores (mNSS) was used to evaluate the neurologic deficits of each rat by an investigator who was blind to the experiment design. The score is composed of sensory, motor, reflex, and balance tests. The degree of neurological deficits is graded on a scale of 0 to 18 (normal score, 0 ; maximal deficit score, 18). Rats with higher score showed more serious injury. Only rats with score of more than 8 at $2 \mathrm{~h}$ after ICH induction were used in the current study. The reduction of mNSS score of each rat is the difference in scores between 14 days after treatment and 1 day after $\mathrm{ICH}$.

\section{Gait analysis}

The TreadScan Gait System (Clever System Inc, USA), consists of a treadmill device and a high-speed digital video camera, was used to obtain and evaluate the gait of the $\mathrm{ICH}$ rats at 14 days after treatment following the provided protocol and previously described [16]. Rats were tested on the treadmill at the speed of $8 \mathrm{~cm} / \mathrm{s}$ for $20 \mathrm{~s}$ sessions, and 2000 digital camera frames were captured. Gait performance was recorded and assessed using the TreadScan software. The gait parameters measured in this study are as follows: stride length, the run speed, print area, foot and pressure.

\section{PET/CT}

Positron-emission tomography/computed tomography (PET/CT) imaging was performed by micro PET/CT (Siemense, German). ${ }^{18} \mathrm{~F}$ - fluorodeoxyglucose $\left({ }^{18} \mathrm{~F}-\mathrm{FDG}\right)$ was prepared at the Department of Nuclear Medicine, Affiliated Hospital of Southwest Medical University. After overnight fast, the rats were injected with approximately $0.8 \mathrm{mCi} / \mathrm{kg}$ of ${ }^{18} \mathrm{~F}-\mathrm{FDG}$ through tail vein, then returned to their home cage to allow the uptake of ${ }^{18} \mathrm{~F}-\mathrm{FDG}$. About 30 min later, the animals were anesthetized with $1 \%$ pentobarbital sodium (40mg/kg, i.p.) and placed in the micro PET/CT scanner. Subsequently, PET scan and CT scan were performed for head imaging (Scan duration $15 \mathrm{~min}$ ). The hemorrhagic foci volume and its glucose uptake were detected by analyzing the PET and CT imaging of rats.

\section{Pathologic examination}

After the neurologic evaluation and PET/CT scans at 14 days post-treatment, the rats were euthanized with an overdose anesthetic drug and perfused transcardially with $0.9 \%$ saline and $4 \%$ paraformaldehyde (PFA), consecutively. Brains were taken out and submerged in PFA for 1 day, and dehydrated in 15\%, and 
$30 \%$ sucrose solution until the brain sank, then embedded in Tissue-Tek ${ }^{\circledR}$ O.C.T.Compound (Sakura Finetek). The brains were cut into $7-\mu \mathrm{m}$ coronal sections on a freezing microtome (Leica CM1850) and stored at $-20^{\circ} \mathrm{C}$. Sections were selected from a region spanning from $-0.4 \mathrm{~mm}$ to $+1.8 \mathrm{~mm}$ with respect to the bregma, and stained with hematoxylin and eosin (HE) for pathomorphological observation.

\section{Assessing the morphological change of mitochondria using TEM}

Dissected caudoputamen samples (the peripheral area of hemorrhagic foci, taking this point located 1.7 $\mathrm{mm}$ lateral to the injection position as the center) were separated into $1 \mathrm{~mm}^{3}$ pieces, then fixed with $3 \%$ glutaraldehyde at $4^{\circ} \mathrm{C}$. The pieces were post-fixed in $1 \%$ osmium tetroxide for $2 \mathrm{~h}$, dehydrated in a gradient series of acetone, infiltrated with propylene epoxide, and finally embedded in Epon 618. Ultra-thin sections $(40 \mathrm{~nm}$ ) were cut with ultramicrotome, collected on copper grids, stained with uranium acetate and lead citrate. Four sections were selected from each group, and seven visual fields in each section were examined with TEM (JEM-1400/1011, Japan). The number of mitochondria was counted in an area of $100 \mu \mathrm{m}^{2}$, and the rate of damaged mitochondrial were calculated with the following formula: rate $=$ (number of damaged mitochondria /total number of mitochondria) $\times 100 \%$.

\section{Enzyme-Linked Immunosorbent Assay (ELISA)}

After anesthesia, blood of rats was collected for preparation of serum and plasma. Brain damage markers and oxidative stress factor contents in serum or plasma were determined by ELISA. According to the manufacturer's instructions, the expression levels of brain damage markers (MBP, NSE, S100B) and oxidative stress factors (MDA and SOD) in the rat serum/plasma were detected by ELISA kits from Novus Biologicals (MBP) and Nanjing Jiancheng Corp. (NSE, S100B, MDA, SOD). The experimental process of different ELISA kits is not exactly the same. Briefly (taking the MBP kit as an example), $100 \mu$ l standard working solution and $100 \mu \mathrm{l}$ diluted sample were added to the corresponding plate wells, and incubated for $90 \mathrm{~min}$ at $37^{\circ} \mathrm{C}$. Remove the liquid out of each well and immediately add $100 \mu \mathrm{L}$ of biotinylated detection Ab working solution to each well, and incubate for 1 hour at $37^{\circ} \mathrm{C}$. After the plate was washed, I00 $\mu \mathrm{l} \mathrm{HRP} \mathrm{conjugate} \mathrm{working} \mathrm{solution} \mathrm{was} \mathrm{added} \mathrm{to} \mathrm{each} \mathrm{well} \mathrm{and} \mathrm{incubated} \mathrm{for} 30$ minutes at $37^{\circ} \mathrm{C}$. After the plate was washed, $90 \mu$ substrate reagent was added to each well and for $15 \mathrm{~min}$ at $37^{\circ} \mathrm{C}$. The reaction was terminated by adding $50 \mu \mathrm{l}$ stop solution. The absorbance values were detected at $450 \mathrm{~nm}$ on a Microplate Reader (Thermo, USA). The standard curve was drawn and the corresponding concentration of the sample was calculated according to the curve equation.

\section{Immunohistochemistryand Immunofluorescence}

Immunohistochemistry was performed as follows. Frozen sections were soaked in phosphate buffer saline (PBS) for $10 \mathrm{~min}$ and then incubated in $0.3 \%$ Triton-X 100 for $10 \mathrm{~min}$. Next, $3 \%$ hydrogen superoxide and $10 \%$ normal goat serum were used to quench endogenous peroxidase activity and block non-specific binding respectively. Following removal of blocking buffer, the sections were incubated with monoclonal anti-rat Bax (1:200, Santa cruz) , Bcl-2 (1:200, Santa cruz), Arg-1 (1:100, CST) and iNOS (1:100, Bioworld) at $4^{\circ} \mathrm{C}$ overnight. Then corresponding biotinylated secondary antibody solution and 
avidin-biotin-peroxidase reagent were added to the sections, and diaminobenzidine was used for colorization. Finally, the samples were counterstained with hematoxylin. Negative controls were identically processed, except that the primary antibody was omitted.

For immunofluorescence, brain slices were washed with PBS for 10 minutes and permeabilized in $0.1 \%$ Triton X-100 solution for 20 min at room temperature, then blocked in $10 \%$ normal goat serum for 30 min. The samples were incubated with monoclonal anti-rat MAP2 (1:200, Santa cruz) at $4^{\circ} \mathrm{C}$ overnight and Alexa Fluor 594-conjugated goat anti-mouse IgG (1:500, Invitrogen) at room temperature for $60 \mathrm{~min}$. Finally, slices were covered with fluorescence mounting medium (Dako).

\section{TdT-mediated dUTP nick-end labeling (TUNEL) staining}

Frozen sections were rinsed three times in PBS and then permeabilized with $0.1 \%$ Triton X-100. After washing two times in PBS, the sections were treated with TUNEL reaction mixture (Roche) for 60 min at $37^{\circ} \mathrm{C}$ in the dark. After washing three times in PBS, the sections were incubated with 4',6-diamidino-2phenylindole (DAPI) for 5 minutes at room temperature, then covered with fluorescence mounting medium. Negative controls were identically processed, except that the TUNEL reaction mixture was omitted.

\section{Western Blotting}

Rats were anesthetized with $1 \%$ pentobarbital sodium and decapitated, then the ipsilateral striatum was immediately taken and quickly frozen in liquid nitrogen until homogenization. Total proteins were extracted from brain samples using radio immunoprecipitation assay (RIPA) lysis buffer (Beyotime) added with phenylmethanesulfonyl fluoride (PMSF) (Beyotime). The protein concentration of the lysates was quantified by the bicinchoninic acid (BCA) protein assay kit (Beyotime). Equal amounts of total protein $(10 \mu \mathrm{g})$ from different samples were resolved by $10-12 \%$ sodium dodecyl sulfate polyacrylamide gel by electrophoresis (SDS-PAGE), then transferred to polyvinylidene difluoride (PVDF) membranes (Millipore) by trans-blot system (Bio-Rad) for detection. The membranes were incubated in blocking buffer (tris-buffer saline-tween, $5 \%$ dried milk) at room temperature for $30 \mathrm{~min}$, following by primary antibodies (BDNF, NGF, COX4, OGDH, PDH-E1a, Bax, Bcl-2, GAPDH and HSP70) at $4^{\circ} \mathrm{C}$ overnight, then secondary horseradish peroxidase (HRP)-labeled goat anti-rabbit or anti-mouse IgG (Bio-Rad) at room temperature for $60 \mathrm{~min}$. The targeted protein bands were visualized with horseradish peroxidase chromogenic Kit (Thermo Fisher), and the density of each band was quantified with an image analysis software (Quantity one). HSP70 or GAPDH was the internal control.

\section{Statistical Analysis}

The statistical analyses were performed with GraphPad Prism 6.0 (San Diego, CA, USA). All data are presented as mean \pm s.e.m. Statistical significance is determined using unpaired Student's t-test between two groups and one-way analysis of variance test for multiple comparisons when comparing multiple groups. $P$ value $<0.05$ was considered to be statistically significant. 


\section{Results}

\section{Electroacupuncture promotes neural differentiation of MSCs in rat with ICH}

MSCs labeled with green fluorescent protein (GFP) (the quality control report of the MSCs derived from SD rat showed in supplementary Fig. 1) grew well after resuscitation (Fig. 1a), and took on neuron-like morphological change with elongated processes and inflated cells bodies after neuronal induction (Fig. 1b). ICH models of rats were established by injecting collagenase and heparin into caudoputamens, and treated with MSCs transplantation or/and electroacupuncture at Baihui and Dazhui after 48 hours (Fig.1c). Immunofluorescence staining showed that the induced exogenous MSCs in rat brains could express the maker (MAP2) of neurons, and the rate of MAP2 positive cells in MSCs+EA group was significantly higher than that in MSCs group (9.34 \pm 0.76 vs $6.05 \pm 0.51 \%, p<0.05 ;$ Fig. $1 \mathrm{~d}, \mathrm{e})$. Furthermore, compared with MSCs group, the expression levels of BDNF and NGF proteins were obviously increased in MSCs+EA group (BDNF: $0.87 \pm 0.02$ vs $0.72 \pm 0.03, p<0.05$; NGF: $0.96 \pm 0.01$ vs $0.74 \pm 0.03, p<0.05$; Fig. $1 f-h$ ).

\section{Combination therapy improves neurological function}

The mNSS scores of all ICH groups were similar before treatment (the data hasn't shown). The reduced scores in the MSCs $(4.60 \pm 0.39)$, EA $(4.95 \pm 0.22)$ and MSCs+EA $(6.55 \pm 0.50)$ groups were significantly more than that in the MC group $(3.25 \pm 0.15, P<0.05)$, and that of MSCs+EA group was most among all groups $(P<0.05$, Fig. 2a).

Gait analysis revealed significant changes in gait functional parameters after ICH (Fig. 2b-k). When compared with MC group, MSCs transplantation, or EA stimulation or combination therapy could improve stride length (four paws), run speed, print area and foot pressure $(P<0.05)$. Furthermore, MSCs+EA groups had better therapeutic effect than MSCs group and EA group on stride length (four paws) and run speed $(P<0.05$, Fig. 2b-k).

\section{Combination therapy improves glycometabolism related to mitochondria}

${ }^{18} \mathrm{~F}-\mathrm{FDG}$ micro-PET/CT scan showed that no hemorrhage focus was observed in the SO group, while the hemorrhage focus was obvious and the glucose uptake decreased in rat after ICH (Fig. 3a-c). Compared with MC group, the volume of hemorrhage focus were smaller in MSCs $\left(61.16 \pm 8.99 \mathrm{~mm}^{3}\right.$ vs $96.86 \pm$ $\left.8.45 \mathrm{~mm}^{3}, P<0.05\right)$, EA $\left(60.47 \pm 5.58 \mathrm{~mm}^{3}\right.$ vs $\left.96.86 \pm 8.45 \mathrm{~mm}^{3}, P<0.05\right)$ and MSCs+EA $(34.78 \pm 6.30$ $\mathrm{mm}^{3}$ vs $\left.96.86 \pm 8.45 \mathrm{~mm}^{3}, P<0.05\right)$ groups, but the levels of glucose uptake were higher in MSCs $(0.83 \pm$ 0.03 vs $0.69 \pm 0.05, P<0.05)$, EA ( $0.82 \pm 0.03$ vs $0.69 \pm 0.48, P<0.05)$ and MSCs+EA $(0.93 \pm 0.02$ vs 0.69 $\pm 0.48, P<0.05)$ groups. In addition, MSCs+EA group had better effect than MSCs and EA groups $(P<0.05$, Fig. 3a-c).

As shown in Fig. 4 (a) by transmission electron microscopy (TEM), the mitochondria were elliptical with dense and dark mitochondrial crista, and no visible vacuole formed in the SO group. However, in the MC group, the mitochondria became swollen and vacuolated partly, and also with fragmented crista in 
ultrastructure. Compared with the MC group, above mitochondrial aberration in structure showed marked improvement, accompanied by the rate of damaged mitochondria decreased in the MSCs $(34.76 \pm 2.94$ vs $51.64 \pm 4.82, P<0.05)$, EA ( $34.38 \pm 2.56$ vs $51.64 \pm 4.82, P<0.05)$ and MSCs+EA $(26.18 \pm 1.86$ vs 51.64 $\pm 4.82, P<0.05$ ) groups (Fig $4 \mathrm{a}, \mathrm{b}$ ). Furthermore, there was no significant difference in the rate of damaged mitochondria between MSCs, EA and MSCs+EA groups ( $P>0.05$, Fig. $4 \mathrm{~b}$ ), but the number of mitochondria in MSCs+EA group (53.80 \pm 3.43 ) was more than that in MSCs (42.20 \pm 2.78$)$ and EA (44.00 \pm 3.52$)$ groups $(P<0.05$, Fig. $4 \mathrm{c})$. Western Blotting showed that the protein expressions of COX4, OGDH and PDHE1 a decreased obviously in rats after ICH $(P<0.05)$, but increased in the MSCs (COX4: $0.42 \pm 0.01$; OGDH: $0.31 \pm 0.03$; PDH-E1a: $0.32 \pm 0.02$ ), EA (COX4: $0.43 \pm 0.01$; OGDH: $0.40 \pm 0.011$; PDH-E1a: $0.38 \pm 0.02$ ) and MSCs+EA (COX4: $0.58 \pm 0.02$; OGDH: $0.51 \pm 0.02$; PDH-E1a: $0.45 \pm 0.03$ ) groups compared with MC group (COX4: $0.29 \pm 0.02 ;$ OGDH: $0.20 \pm 0.02$; PDH-E1a: $0.22 \pm 0.02)(P<0.05$, Fig. $4 \mathrm{~d}-\mathrm{g})$. Moreover, the expression levels of these three proteins were higher in MSCs+EA group than in MSCs and EA groups $(P<0.05$, except for level of PDH-E1a protein between MSCs+EA group and EA group, Fig. 4e-g).

\section{Combined therapy improves the structure of brain tissue and alleviates brain injury}

The coronal sections of brains and hematoxylin-eosin (HE) staining showed that the hemorrhagic regions were located mainly to the striatum, and hemorrhage foci were visible in all ICH groups, but which in the different treatment groups were alleviated to varying degrees when compared with MC group (Fig. $5 a, b)$.

The results of ELISA showed that the level of MDA in serum was $2.69 \pm 0.13 \mathrm{nmol} / \mathrm{L}$ in the MC group vs $1.69 \pm 0.12 \mathrm{nmol} / \mathrm{L}$ in the SO group $(P<0.05)$, and the SOD activity in plasma was $92.55 \pm 1.46 \mathrm{U} / \mathrm{L}$ in the $\mathrm{MC}$ group vs $120.01 \pm 1.17 \mathrm{U} / \mathrm{L}$ in the SO group $(P<0.05)$ (Fig. $5 \mathrm{c}$, d). Compared with MC group, markedly down-regulation of the MDA level and increase of SOD activity were observed in the MSCs (MDA: $2.26 \pm$ $0.06 \mathrm{nmol} / \mathrm{L}, P<0.05$; SOD: $105.20 \pm 1.43 \mathrm{U} / \mathrm{L}, P<0.05$ ), EA (MDA: $2.25 \pm 0.04 \mathrm{nmol} / \mathrm{L}, P<0.05$; SOD: $101.70 \pm 1.59 \mathrm{U} / \mathrm{L}, P<0.05)$ and MSCs+EA (MDA: $1.88 \pm 0.05 \mathrm{nmol} / \mathrm{L}, P<0.05 ;$ SOD: $113.00 \pm 1.76 \mathrm{U} / \mathrm{L}$, $P<0.05)$ groups. In addition, level of MDA decreased and SOD activity improved significantly in MSCs+EA group when compared with that in MSCs and EA groups ( $P<0.05$, Fig. $5 \mathrm{c}, \mathrm{d})$. To further study the effect of EA stimulation on MSCs transplantation in the severity of brain injury in ICH rats, the levels of MBP, NSE and S100B in serum were also examined by ELISA. The results displayed that the levels of MBP, NSE and S100-B increased significantly in the MC group (MBP: $2732.36 \pm 57.67 \mathrm{ng} / \mathrm{L}$ vs $860.95 \pm 135.20$ $\mathrm{ng} / \mathrm{L}, P<0.05$; NSE: $2960.23 \pm 74.25 \mu \mathrm{g} / \mathrm{L}$ vs $420.20+82.40 \mu \mathrm{g} / \mathrm{L}, P<0.05 ; \mathrm{S} 100-\mathrm{B}: 147.14 \pm 1.58 \mathrm{ng} / \mathrm{L}$ vs $49.11 \pm 7.69 \mathrm{ng} / \mathrm{L}, P<0.05)$ when compared with that in the SO group. After treatment, the levels of MBP and NSE declined markedly in MSCs $(2202.34 \pm 82.58 \mathrm{ng} / \mathrm{L}$ and $2537.41 \pm 130.50 \mu \mathrm{g} / \mathrm{L}$ respectively, $P<0.05), \mathrm{EA}(2168.75 \pm 37.92 \mathrm{ng} / \mathrm{L}$ and $2595.99 \pm 53.30 \mu \mathrm{g} / \mathrm{L}$ respectively, $P<0.05)$ and MSCs+EA $(1707.61 \pm 66.71 \mathrm{ng} / \mathrm{L}$ and $2155.92 \pm 32.88 \mu \mathrm{g} / \mathrm{L}$ respectively, $P<0.05)$ groups (Fig. 5e-g). Furthermore, the levels of MBP and NSE in MSCs+EA group were lower than that in the MSCs and EA groups $(P<0.05$, Fig. $5 e, f)$, and the level of S100B in MSCs+EA group $(121.79 \pm 2.54 \mathrm{ng} / \mathrm{L})$ were lower than that in MC group $(147.14 \pm 1.58 \mathrm{ng} / \mathrm{L})(P<0.05$, Fig. $5 \mathrm{~g})$. 


\section{Combined therapy reduces cell apoptosis}

TUNEL-positive cells were localized mainly in peripheral regions of lesions. The number of apoptotic cells was $77.60 \pm 4.32$ in MC group vs $2.80 \pm 0.58$ in SO group $(P<0.05)$, and decreased significantly in MSCs $(29.40 \pm 1.33, P<0.05)$, EA $(30.80 \pm 2.35, P<0.05)$ and MSCs+EA $(18.80 \pm 0.86, P<0.05)$ groups when compared with MC group (Fig. 6a,b). In addition, EA stimulation could reduced further the number of apoptotic cells in ICH rats following MSCs transplantation $(P<0.05$, Fig. 6a,b). Immunohistochemistry and western blotting analyses showed that the level of Bax protein increased, however level of Bcl-2 protein decreased in rats after ICH (Fig. 7a-d). Bcl-2 expression increased in MSCs (0.36 \pm 0.03$)$, EA (0.28 \pm 0.02$)$ and MSCs+EA (1.17 \pm 0.03$)$ groups, but Bax expression decreased in MSCs $(0.34 \pm 0.02)$, EA $(0.35 \pm 0.02)$ and MSCs+EA $(0.20 \pm 0.01)$ groups in comparison with MC group (Bcl-2: $0.15 \pm 0.01$; Bax:1.53 \pm 0.04$)$ $(P<0.05$, Fig. 7a-d). Moreover, the level of Bcl-2 protein was higher and the level of Bax protein was lower in MSCs+EA group than those in the MSCs and EA groups ( $P<0.05$, Fig. 7a-d).

\section{Combined therapy alleviates the inflammatory reaction after cerebral hemorrhage}

Microglia are the crucial immune cells in the central nervous system (CNS). Generally, they include two phenotypes of polarization: M1 type and M2 type. Immunohistochemistry showed that the number of microglial cells (including M1 and M2 types) increased in rats after ICH. The number of Arg-1 (M2 marker) positive cells was more in MSCs (69.20 \pm 1.39$)$, EA (63.40 \pm 1.33$)$ and MSCs+EA (101.00 \pm 3.96$)$ groups than in MC group $(35.60 \pm 1.21)(P<0.05$, Fig. 8a,c). However, the number of iNOS (M1 marker) positive cells was less in MSCs (54.00 \pm 1.41$)$, EA (56.60 \pm 2.42$)$ and MSCs+EA (45.60 \pm 1.57$)$ groups than in MC group $(90.20 \pm 1.56)(P<0.05$, Fig. 8b,d). Compared with MSCs and EA groups, the number of Arg-1 positive cells increased but the number of iNOS positive cells decreased in MSCs+EA group $(P<0.05$, Fig. 8a-d).

\section{Discussion}

The present study investigated the hypothesis that EA stimulation could improve therapeutic effects of MSCs transplantation in rats subjected to $\mathrm{ICH}$. To do this, we evaluated neurobehavioral function, differentiation of transplanted cells, ultrastructure of mitochondrion, volume of hemorrhagic foci and glucose uptake, cell apoptosis, inflammatory reaction, structural changes of brain tissue, etc. Results showed that EA stimulation further alleviates brain injury and improves neurologic deficit symptoms through a variety of pathways in ICH rats after MSCs transplantation.

Although successful neuroregeneration in the adult brain offers an attractive therapeutic prospect for brain injuries such as $\mathrm{ICH}$, only finite number of mature cells developed from neuronal progenitor cells have been found to provide cellular renewing $[17,18]$. Thus, transplantation of exogenous cells can be an effective strategy for cell renewing in the damaged brain, and stem cell therapy has exhibited good neuroprotective and neurorestorative effect in $\mathrm{ICH}$ and is a promising therapeutic method [19]. A variety of stem cells, including MSCs, neural stem cells (NSCs), embryonic stem cells (ESCs) and induced pluripotent stem cells (iPSCs), have been used to treatment for experimental ICH [19]. MSCs can be 
derived from various adult tissues. The characteristics of presenting no major ethical concerns, having multidirectional differentiation potential and low immunogenicity, possessing self-renewal ability and immune modulation functions, and improving microenvironment make MSCs promising candidates for stem cell therapy $[11,19,20]$.

However, strategies to ameliorate the low neural differentiation of transplanted MSCs are still under investigation. EA is one of the main healing arts in Oriental medicine. Previous studies have shown that EA can increase the synthesis and secretion of neurotrophic factors (NTFs), such as brain-derived neurotrophic factor (BDNF), neurotrophin (NT) and glial-derived neurotrophic factor (GDNF), which have protective effects on neural tissues and are helpful for differentiation of stem cells in brain [21,22]. Ahn $\mathrm{SM}$ et al. reported that EA treatment could promote differentiation of grafted MSCs into astrocyte- or neuron-like cells in mice with ischemic stroke [22]. Here, we also present evidence that EA stimulation increase the synthesis of BDNF and NGF, and promote neuronal differentiation of transplanted MSCs.

There is accumulating evidence that both MSCs transplantation and electroacupuncture stimulation can improve recovery after hemorrhagic brain injury via various pathways [9,23-25]. Several studies have shown that combined MSCs with EA treatment may lead to a better therapeutic effect in restoring the motor function of both paws and alleviating atrophic changes of the striatum in mice with MCAO, and improving remyelination and function in demyelinated spinal cord of rats [22,26,27]. The results from our behavioral, hematological and histological studies showed that both MSCs transplantation and EA stimulation improved neuronal deficit function, increased the concentration of SOD and decreased the levels of MDA, MBP, NSE and S100B in ICH rat, what counts is that a better synergistic effect of combined MSCs and EA to restore the motor function and alleviate oxidative stress and brain damage was observed.

The process of $\mathrm{ICH}$ has always been accompanied by neuroinflammatory reaction characterized by microglial activation. Activation of microglia is considered to be a double-edged sword in ICH disease [28]. Increasing evidence points out that microglia within the CNS milieu appear to be heterogeneous with opposite functional phenotypes that range from cytotoxic M1 phenotype to neuroprotective M2 phenotype [29]. The changes of microglial phenotypes rely on the disease stages and severity, and mastering the stages transformation of $\mathrm{M} 1 / \mathrm{M} 2$ phenotypes within appropriate time windows may offer better therapeutic benefit [29]. Microglia produce M1 and M2 phenotypes to respond to brain damage in $\mathrm{ICH}$ pathology [30]. Our date showed that either proinflammatory M1 or anti-inflammatory M2 microglia increased in rats after ICH. Furthermore, MSCs or EA administration supressed microglia polarization to the $\mathrm{M} 1$ phenotype and instead increased a shift to the M2 phenotype. Alternatively activated M2 microglia might accelerate phagocytosis of tissue debris and erythrocytes, a major contribution to haematoma clearance [30]. In addition, EA stimulation can enhance the effects of MSCs transplantation in rat after $\mathrm{ICH}$.

The pathologic processes after $\mathrm{ICH}$ are intricate. $\mathrm{ICH}$ can not only cause excitotoxicity, reactive oxygen species (ROS) generation, oxidative stress and inflammation response, but also lead to mitochondrial 
injury and dysfunction [31-33]. Neurons are hypersensitive to energy changes and need to keep up mitochondrial stability to provide enough energy, and mitochondria injury can lead to neuronal apoptosis [34-37]. It has been shown that hMSC transplantation in the treatment of cerebral hemorrhage can improve the accumulation of serial ${ }^{18} \mathrm{~F}-\mathrm{FDG}$ PET in the paralateral basal ganglia [38]. Zhang $\mathrm{J}$ et al. reported that EA reversed mitochondrial damage and improved mitochondrial functions in hippocampus in depressed rats [39]. Bao CL et al. indicated that EA could improve the energy metabolism, raise the activity of chondriosome, and decrease the accumulation of lactate acid in the perihemotoma tissue of $\mathrm{ICH}$ rats [40]. Our experiment showed that the treatments of both MSCs and EA increased the level of glucose uptake in focal area, meanwhile, increased the expressions of mitochondrial enzyme (COX4, OGDH and PDH-E1a) and improved ultrastructure of mitochondria. Interestingly, EA could enhance the effect of MSCs transplantation therapy on mitochondria and further reduced the hemorrhagic volume. These data suggest that the combined treatment of MSCs and EA plays an important role in maintaining the stability of mitochondrial structure and function which is helpful to promote cell survival.

Apoptosis was an important mechanism of early tissue injury in the region around the hematoma after $\mathrm{ICH}$. Many factors could induce cell apoptosis after $\mathrm{ICH}$, such as inflammation, free radical cascade reaction, cytokine stimulation, mitochondrial structural damage and dysfunction, the induction of thrombin and blood components [41]. In addition, various genes were also involved in regulating neuronal apoptosis, including Bcl-2 which inhibited apoptosis and Bax which promoted apoptosis [42]. MSCs transplantation could upregulate Bcl-2 expression and reduce apoptosis in ICH rat [43]. Our previous studies also showed that MSCs administration reduced cell apoptosis, and EA increased Bcl-2 expression but decreased Bax expression in rat after $\mathrm{ICH}[15,16]$. In this study, we found that MSCs combinated with EA has the synergetic effects in reducing neuronal apoptosis and regulating apoptotic relative proteins in $\mathrm{ICH}$ rat.

There are some shortcomings in the present study, and one of the limitations is that it only comprised a time point; thus, the short or long-term effects of combination therapy of MSCs and EA on ICH remain unclear. Moreover, only the effects of combination therapy on mitochondria, oxidative stress, apoptosis, neuroinflammation, and other brain injury were investigated, but the mechanisms were not characterized. Furthermore, the survival time of MSCs in the brain was not examined, although we observed that MSCs could survive in $\mathrm{ICH}$ rat brain.

In summary, notwithstanding limitations of this study, to the best of our knowledge we firstly reported that to some extent, EA enhance therapeutic efficacy of MSCs transplantation in rats with ICH. Of course, the major mechanisms and the key targets of combination therapy of MSCs and EA involved in offering neuroprotective effects for ICH showed in this study would be explored in our future work.

\section{Conclusion}

In the present study, we demonstrated that whether MSCs transplantation or EA stimulation, generates neuroprotective effects in hemorrhagic brain injury, and found that combination treatment of MSCs and 
EA produced better synergistic effects in improvement of neurological dysfunction and protecting brain tissues after $\mathrm{ICH}$ by impacting mitochondrial structure and function, neuroinflammation, oxidative stress, and apoptosis. Our findings suggest that the administration of MSCs combined with EA may be a novel therapeutic strategy against hemorrhagic injury.

\section{Supplementary Material}

The rat MSCs isolated from bone marrow were positive for CD44 (98.56\%) and CD90 (98.5\%) and negative for CD $45(0.04 \%)$, CD34 (1.17\%) and CD11b/c (0.68\%) by flow cytometry (Supplementary Fig. 1a-e). Fluorescence rate of MSCs labeled with GFP was $96.83 \%$ (Supplementary Fig. 1f).

\section{Declarations}

\section{Acknowledgments}

We thank Yue Feng for his help on PET/CT and thank the member of Interest Group on Neurobiology (including Yu liu, Hongyu Chen, Youhua Wang, Jing Li, Bing Xiao, Hongyan He, Jun Wang, Jinyi Li and Chuan Tang) for help on animal experiment.

\section{Author Contributions}

CXY conceived and designed the experiments. $L D, L Z, Y Z, G B F, H J T, Y J Z, P Z, X Q G, K G$ performed the experiments and analyzed the data; and CXY and PZ wrote the manuscript. All authors read and approved the final version of the manuscript.

\section{Funding}

This study was supported by Natural Science of the Zhejiang Province Foundation of China (LY19H090009 and LY20H090010 to PZ ), the Research Project of Science Foundation of Sichuan Province Educational Commission of China (18ZA0516 to CXY), the Joint Research Project of Luzhou Municipal People's Government and Southwest Medical University (2018LZXNYD-ZK35 to CXY) and Application Basic Research Project of Sichuan Province of China (2013JY0075 to CXY).

\section{Data availability}

The data that support the findings of this study are available from the corresponding author upon reasonable request.

\section{Ethics approval and consent to participate}

All procedures involving animals were approved by the Animal Care and Use Committee at the Southwest Medical University and conducted in accordance with the national guidelines on animal care. 
Not applicable.

\section{Competing interests}

The authors declare no competing interests.

\section{Author details}

${ }^{1}$ Department of Anatomy, College of Basic Medicine, Southwest Medical University, Luzhou 646000, People's Republic of China. ${ }^{2}$ Clinical Skills Center, Affiliated Hospital of Southwest Medical University, Luzhou 646000, People's Republic of China. ${ }^{3}$ Department of Neurobiology, Preclinical Medicine Research Center, Southwest Medical University, Luzhou 646000, People's Republic of China. ${ }^{4}$ Institute of Neuroscience, Basic Medical College of Wenzhou Medical University, Wenzhou 325035, People's Republic of China.

\section{Abbreviations}

MSCs: Mesenchymal stem cells; ICH: Intracerebral hemorrhage; EA: Electroacupuncture; MDA: Malondialdehyde; SOD: Superoxide dismutase; NSE: Neuron-specific enolase; S100B: S100beta; MBP: Myelin basic protein; COX4: Cytochrome c oxidase subunit IV; OGDH: 2-oxoglutarate dehydrogenase; PDH: pyruvate dehydrogenase; TUNEL: Terminal deoxynucleotidyl transferase (TdT) dUTP nickend labeling; TEM: Transmission electron microscopy; SD: Sprague-Dawley; GFP: Green fluorescent protein; a-MEM: Alpha-minimum essential medium; $\beta$-ME: $\beta$-mercaptoethanol; DMSO: Dimethylsulfoxide; RA: Retinoic acid; PET/CT: Positron-emission tomography/computed tomography; FDG: Fluorodeoxyglucose; mNSS: Modified neurological severity scores; PFA: Paraformaldehyde; ELISA: Enzyme-linked immunosorbent assay; PBS: Phosphate buffer saline; DAPI: 4',6-diamidino-2-phenylindole; RIPA: Radio immunoprecipitation assay; PMSF: Phenylmethanesulfonyl fluoride; SDS-PAGE: Sodium dodecyl sulfate polyacrylamide gel by electrophoresis; PVDF: Polyvinylidene difluoride; BDNF: Brainderived neurotrophic factor; NGF: Nerve growth factor; GAPDH: Glyceraldehyde-3-phosphate dehydrogenase; HSP70: Heat shock protein 70; HRP: Horseradish peroxidase; MAP2: Microtubuleassociated protein-2; CD: Cluster of differentiation

\section{References}

1. Broderick J, Connolly S, Feldmann E, Hanley D, Kase C, Krieger D, Mayberg M, Morgenstern L, Ogilvy CS, Vespa P, et al (2007). Guidelines for the management of spontaneous intracerebral hemorrhage in adults: a guideline from the American Heart Association/American Stroke Association Stroke Council, High Blood Pressure Research Council, and the quality of care and outcomes in Research Interdisciplinary Working Group. Stroke. 38(6): 2001-2023.

2. Qureshi Al, Tuhrim S, Broderick JP, Batjer HH, Hondo H, Hanley DF (2001). Spontaneous intracerebral hemorrhage. N Engl J Med. 344(19): 1450-1460. 
3. Lule S, Wu L, McAllister LM, Edmiston WJ III, Chung JY, Levy E, Zheng Y, Gough PJ, Bertin J, Degterev $A$, et al(2017). Genetic inhibition of receptor interacting protein kinase-1 reduces cell death and improves functional outcome after intracerebral hemorrhage in mice. 48(9): 2549-2556.

4. Chen-Roetling J, Kamalapathy P, Cao Y, Song W, Schipper HM, Regan RF (2017). Astrocyte heme oxygenase-1 reduces mortality and improves outcome after collagenase-induced intracerebral hemorrhage. Neurobiol Dis.102:140-146.

5. Hammond MD, Taylor RA, Mullen MT, Ai Y, Aguila HL, Mack M, Kasner SE, McCullough LD, Sansing LH (2014). CCR2+ Ly6C(hi) inflammatory monocyte recruitment exacerbates acute disability following intracerebral hemorrhage. J Neurosci. 34(11): 3901-3909.

6. Min S, Kim OJ, Bae J, Chung TN (2018). Effect of pretreatment with the NADPH oxidase inhibitor apocynin on the therapeutic efficacy of human placenta-derived mesenchymal stem cells in intracerebral hemorrhage. Int J Mol Sci. 19(11):3679.

7. Choi BY, Kim OJ, Min SH, Jeong JH, Suh SW, Chung TN (2018). Human placenta-derived Mesenchymal Stem Cells Reduce Mortality and Hematoma Size in a Rat Intracerebral hemorrhage model in an acute phase. Stem Cells Int. 2018:1658195.

8. Kim K, Park HW, Moon HE, Kim JW, Bae S, Chang JW, Oh W, Yang YS, Paek SH (2015). The effect of human umbilical cord blood-derived mesenchymal stem cells in a collagenase-induced intracerebral hemorrhage rat model. Exp Neurobiol. 24(2): 146-155.

9. Huang P, Freeman WD, Edenfield BH, Brott TG, Meschia JF, Zubair AC (2019). Safety and efficacy of intraventricular delivery of bone marrow-derived mesenchymal stem cells in hemorrhagic stroke model. Sci Rep. 9(1): 5674.

10. Chen M, Li X, Zhang X, He X, Lai L, Liu Y, Zhu G, Li W, Li H, Fang Q, et al (2015). The inhibitory effect of mesenchymal stem cell on blood-brain barrier disruption following intracerebral hemorrhage in rats: contribution of TSG-6. J Neuroinflammation. 12: 61.

11. Bedini G, Bersano A, Zanier ER, Pischiutta F, Parati EA (2018). Mesenchymal stem cell therapy in intracerebral haemorrhagic stroke. Curr Med Chem. 25(19): 2176-2197.

12. Cai Y, Zhang CS, Liu S, Wen Z, Zhang AL, Guo X, Lu C, Xue CC (2017). Electroacupuncture for poststroke spasticity: a systematic review and meta-analysis. Arch Phys Med Rehabil. 98(12): 25782589.

13. Lee S, Kim W, Park J, Jang HH, Lee SM, Woo JS, Kim HS, Lee KH, Kwon YJ, Lee U, et al (2015). Effects of electroacupuncture on endothelial function and circulating endothelial progenitor cells in patients with cerebral infarction. Clin Exp Pharmacol Physiol. 42(8): 822-827.

14. Xing $Y$, Zhang $M$, Li WB, Dong F, Zhang $F$ (2018). Mechanisms involved in the neuroprotection of electroacupuncture therapy for ischemic stroke. Front Neurosci.12: 929.

15. Yang C, Zhou L, Gao X, Chen B, Tu J, Sun H, Liu X, He J, Liu J, Yuan Q (2011). Neuroprotective effects of bone marrow stem cells overexpressing glial cell line-derived neurotrophic factor on rats with intracerebral hemorrhage and neurons exposed to hypoxia/reoxygenation. Neurosurgery. 68(3): 691704. 
16. Zhu Y, Deng L, Tang H, Gao X, Wang Y, Guo K, Kong J, Yang C (2017). Electroacupuncture improves neurobehavioral function and brain injury in rat model of intracerebral hemorrhage. Brain Res Bull. 131:123-132.

17. Zhou L, Deng L, Chang NB, Dou L, Yang CX (2014). Cell apoptosis and proliferation in rat brains after intracerebral hemorrhage: role of Wnt/ß-catenin signaling pathway. Turk J Med Sci.44(6): 920-927.

18. Shimamura N, Kakuta K, Wang L, Naraoka M, Uchida H, Wakao S, Dezawa M, Ohkuma H (2017). Neuro-regeneration therapy using human muse cells is highly effective in a mouse intracerebral hemorrhage model. Exp Brain Res. 235(2): 565-572.

19. Gao L, Xu W, Li T, Chen J, Shao A, Yan F, Chen G (2018). Stem cell therapy: a promising therapeutic method for intracerebral hemorrhage. Cell Transplant. 27(12):1809-1824.

20. Shahror RA, Linares GR, Wang Y, Hsueh SC, Wu CC, Chuang DM, Chiang YH, Chen KY (2020). Transplantation of mesenchymal stem cells overexpressing fibroblast growth factor 21 facilitates cognitive recovery and enhances neurogenesis in a mouse model of traumatic brain injury. $\mathrm{J}$ Neurotrauma.37(1): 14-26.

21. Shin HK, Lee SW, Choi BT (2017). Modulation of neurogenesis via neurotrophic factors in acupuncture treatments for neurological diseases. Biochem Pharmacol. 141:132-142.

22. Ahn SM, Kim YR, Shin Yl, Ha KT, Lee SY, Shin HK, Choi BT (2019). Therapeutic potential of a combination of electroacupuncture and trkB-expressing mesenchymal stem cells for ischemic stroke. Mol Neurobiol. 56(1): 157-173.

23. Li HQ, Li Y, Chen ZX, Zhang XG, Zheng XW, Yang WT, Chen S, Zheng GQ (2016). Electroacupuncture exerts neuroprotection through caveolin-1 mediated molecular pathway in intracerebral hemorrhage of rats. Neural Plast. 2016:7308261.

24. Zhou HJ, Tang T, Zhong JH, Luo JK, Cui HJ, Zhang QM, Zhou JH, Zhang Q (2014).

Electroacupuncture improves recovery after hemorrhagic brain injury by inducing the expression of angiopoietin-1 and -2 in rats. BMC Complement Altern Med. 14:127.

25. Zhang H, Wang Y, Lv Q, Gao J, Hu L, He Z (2018). MicroRNA-21 overexpression promotes the neuroprotective efficacy of mesenchymal stem cells for treatment of intracerebral hemorrhage. Front Neurol. 9: 931.

26. Kim YR, Ahn SM, Pak ME, Lee HJ, Jung DH, Shin YI, Shin HK, Choi BT (2018). Potential benefits of mesenchymal stem cells and electroacupuncture on the trophic factors associated with neurogenesis in mice with ischemic stroke. Sci Rep. 8(1): 2044.

27. Ding Y, Zhang RY, He B, Liu Z, Zhang K, Ruan JW, Ling EA, Wu JL, Zeng YS (2015). Combination of electroacupuncture and grafted mesenchymal stem cells overexpressing TrkC improves remyelination and function in demyelinated spinal cord of rats. Sci Rep. 5: 9133.

28. Tschoe C, Bushnell CD, Duncan PW, Alexander-Miller MA, Wolfe SQ (2020). Neuroinflammation after intracerebral hemorrhage and potential therapeutic targets. Journal of Stroke. 22(1):29-46.

29. Tang Y, Le W (2016). Differential roles of M1 and M2 microglia in neurodegenerative diseases. Mol Neurobiol. 53(2):1181-1194. 
30. Lan X, Han X, Li Q, Yang QW, Wang J (2017). Modulators of microglial activation and polarization after intracerebral haemorrhage. Nat Rev Neurol. 13(7):420-433.

31. Wang Z, Zhou F, Dou Y, Tian XD , Liu CL , Li HY, Shen HT , Chen G (2018). Melatonin alleviates intracerebral hemorrhage-induced secondary brain injury in rats via suppressing apoptosis, inflammation, oxidative stress, DNA damage, and mitochondria injury. Transl Stroke Res. 9(1): 74-91.

32. Chen S, Yang Q, Chen G, Zhang JH (2015). An update on inflammation in the acute phase of intracerebral hemorrhage. Transl Stroke Res. 6: 4-8.

33. Ning Wei, Yinghai Wei, Binru Li, Linlin Pang (2017). Baicalein promotes neuronal and behavioral recovery after intracerebral hemorrhage via suppressing apoptosis, oxidative stress and neuroinflammation. Neurochem Res. 42(5): 1345-53.

34. Du X, Carvalho-de-Souza JL, Wei C, Carrasquel-Ursulaez W, Lorenzo Y, Gonzalez N, Kubota T, Staisch $J$, Hain T, Petrossian N, et al (2020). Loss-of-function BK channel mutation causes impaired mitochondria and progressive cerebellar ataxia. Proc Natl Acad Sci USA. 117(11): 6023-6034.

35. Zsurka G, Kunz WS (2015). Mitochondrial dysfunction and seizures: the neuronal energy crisis. Lancet Neurol. 14(9): 956-66.

36. Vanhauwaert R, Bharat V, Wang X (2019). Surveillance and transportation of mitochondria in neurons. Curr Opin Neurobiol. 57: 87-93.

37. Han S, Nandy P, Austria Q, Siedlak SL, Torres S, Fujioka H, Wang W, Zhu X (2020). Mfn2 ablation in the adult mouse hippocampus and cortex causes neuronal death. Cells. 9(1): 116.

38. Feng M, Zhu H, Zhu Z, Wei J, Lu S, Li Q, Zhang N, Li G, Li F, Ma W, et al (2011). Serial 18F-FDG PET demonstrates benefit of human mesenchymal stem cells in treatment of intracerebral hematoma: a translational study in a primate model. J Nucl Med. 52(1): 90-97.

39. Zhang J, Zhang Z, Zhang J, Zhong Z, Yao Z, Qu S, Huang Y (2019). Electroacupuncture improves antidepressant effects in CUMS rats by protecting hippocampal synapse and mitochondrion: an ultrastructural and iTRAQ proteomic study. Evid Based Complement Alternat Med. 2019: 3424698.

40. Bao CL, Dong HS (2008). Effect of scalp-acupuncture on energy metabolism of brain tissue in intracerebral hemorrhage rats. Zhen Ci Yan Jiu. 33(2):93-97.

41. Wang Z, Zhou F, Dou Y, Tian X, Liu C, Li H, Shen H, Chen G (2018). Melatonin Alleviates Intracerebral Hemorrhage-Induced Secondary Brain Injury in Rats via Suppressing Apoptosis, Inflammation, Oxidative Stress, DNA Damage, and Mitochondria Injury. Transl Stroke Res. 9(1):74-91.

42. Lončarević-Vasiljković $N$, Milanović $D$, Pešić $V$, Tešić $V$, Brkić $M$, Lazić $D$, Avramović $V$, Kanazir $S$ (2016). Dietary restriction suppresses apoptotic cell death, promotes Bcl-2 and Bcl-xl mRNA expression and increases the $\mathrm{Bcl}-2 / \mathrm{Bax}$ protein ratio in the rat cortex after cortical injury. Neurochem Int. 96:69-76.

43. Wang SP, Wang ZH, Peng DY, Li SM, Wang H, Wang XH (2012). Therapeutic effect of mesenchymal stem cells in rats with intracerebral hemorrhage: reduced apoptosis and enhanced neuroprotection. Mol Med Rep. 6(4): 848-854. 


\section{Figures}
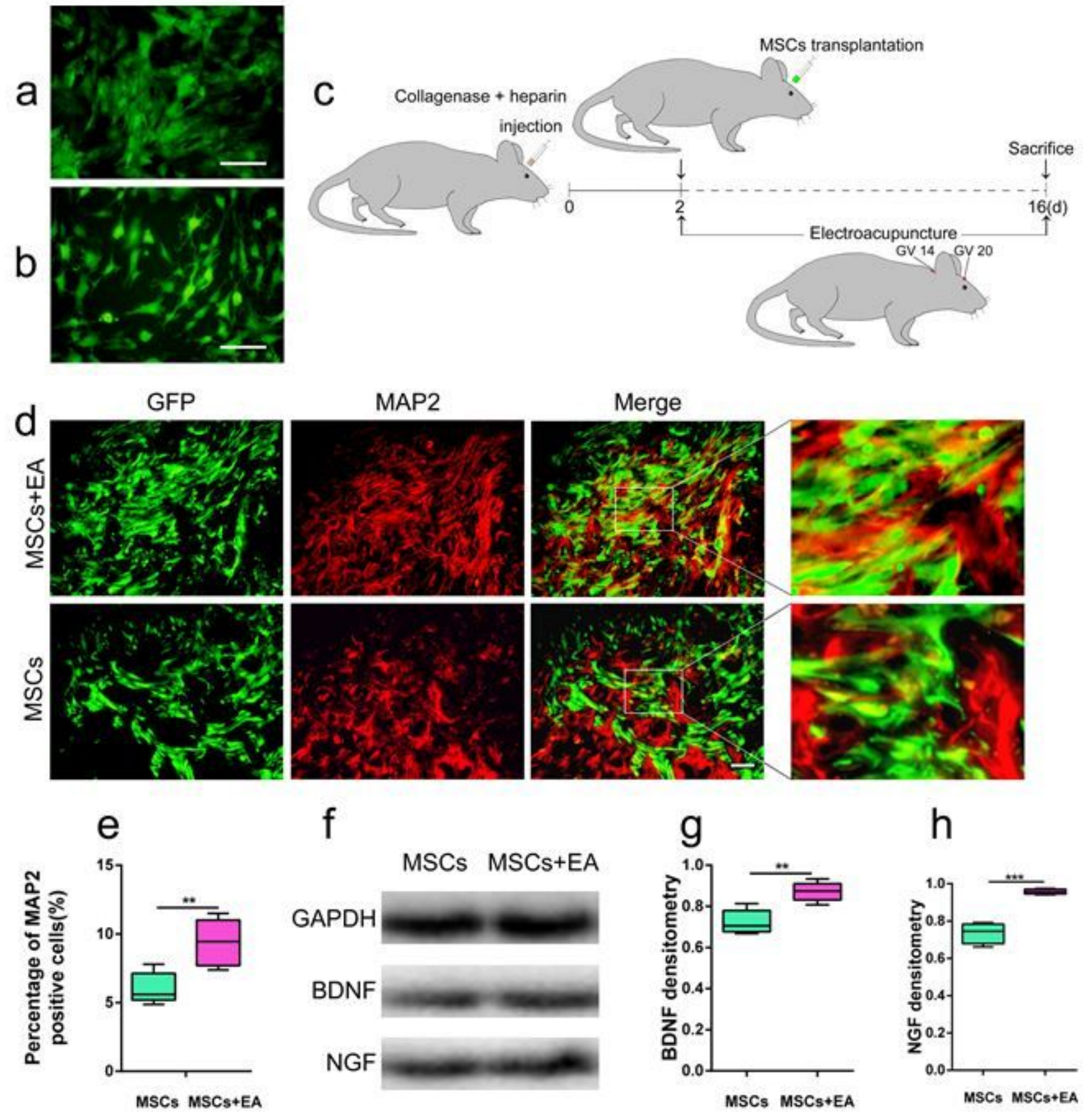

\section{Figure 1}

EA promote neural differentiation of MSCs in rat brain with $\mathrm{ICH}$. a Cultured MSCs labeled with green fluorescent protein (GFP) (Scale bars, $100 \mu \mathrm{m}$ ). b MSCs induced by neuronal induction medium (Scale bars, $100 \mu \mathrm{m})$. c The timeline depicts the periods of $\mathrm{ICH}$ and shows the treatment protocol for administration of EA stimulation and/or MSCs transplantation. $d$ Neural differentiation of MSCs after transplantation (Scale bars, $100 \mu \mathrm{m}$ ). e The rate of MAP2-positive cells among the MSCs after 
transplantation $\left(n=5\right.$ per group; $\left.{ }^{\star *} p<0.01\right)$. $f$ The expressions of BDNF and NGF in peripheral region of hematoma on day 14 , shown by Western blotting. $\mathrm{g}$-h The relative values of the proteins of BDNF $(\mathrm{g})$ and NGF (h) on day 14 determined by Western blotting ( $n=5$ per group; $* * p<0.01$, and $* * * p<0.005$ ).
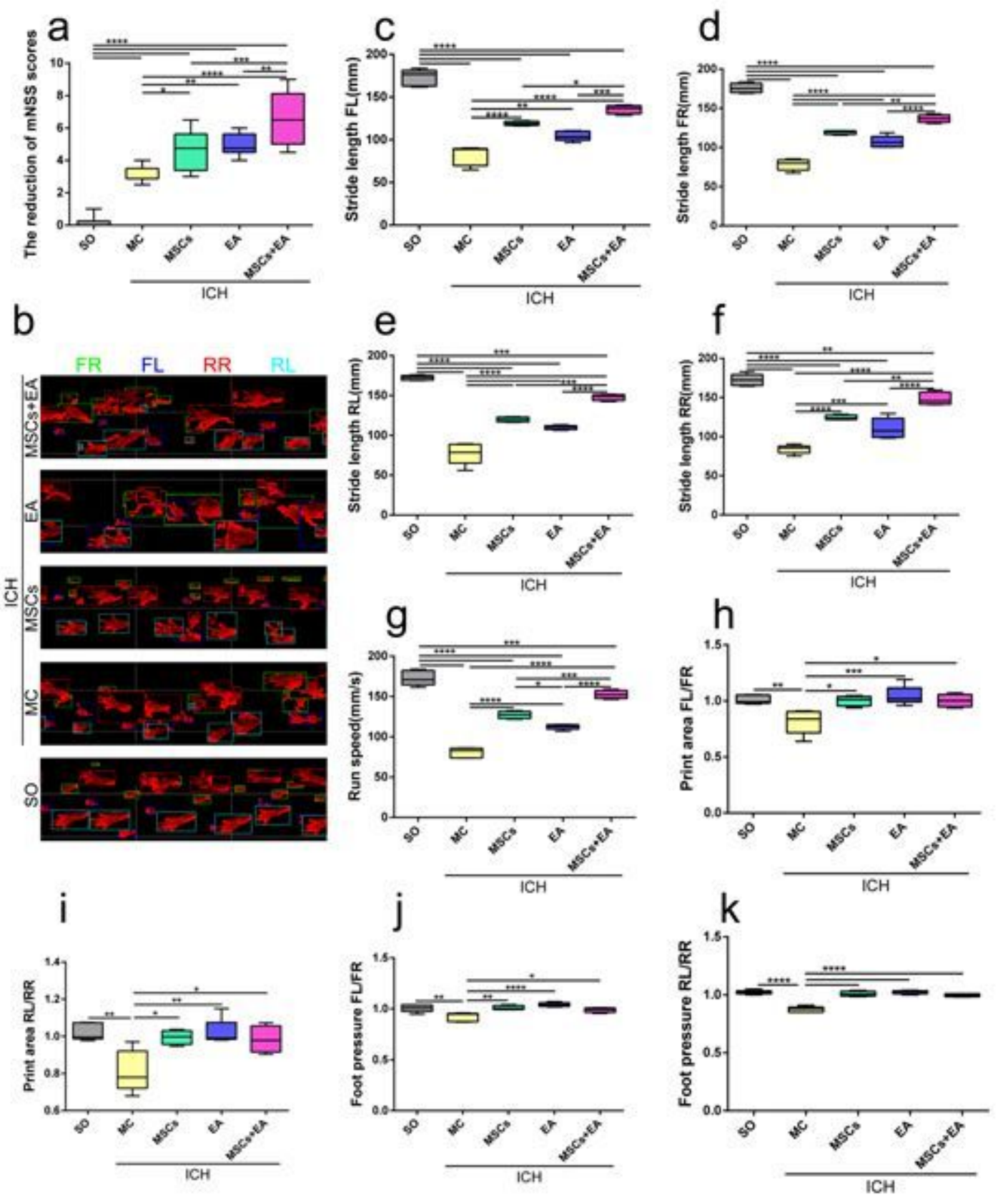

Figure 2

Neurological deficits were measured by mNSS and animal gait analysis system. a Neurological functional test by mNSS after ICH ( $n=5$ per group; $* P<0.05$, ${ }^{\star *} P<0.01$, and $\left.* \star \star * P<0.0001\right)$. $b$ Representative paw prints(red prints in black background)in the analysis software from rats of different groups. FR (green): front right paw; FL (dark-blue): front left paw; RR(red): rear right paw; RL (sky-blue): rear left paw. c-s Gait analysis reveals impaired limb function in ICH rats. Gait parameters (including Stride length, Run speed, Print area, Foot pressure) were analyzed using GAIT SCAN analysis software in 
rats $\left(n=4-5\right.$ per group; ${ }^{*} P<0.05,{ }^{*} P<0.01,{ }^{\star} * * P<0.001$, and $\left.* \star \star \star P<0.0001\right)$. FR: front right paw; FL: front left paw; RR: rear right paw; RL: rear left paw.

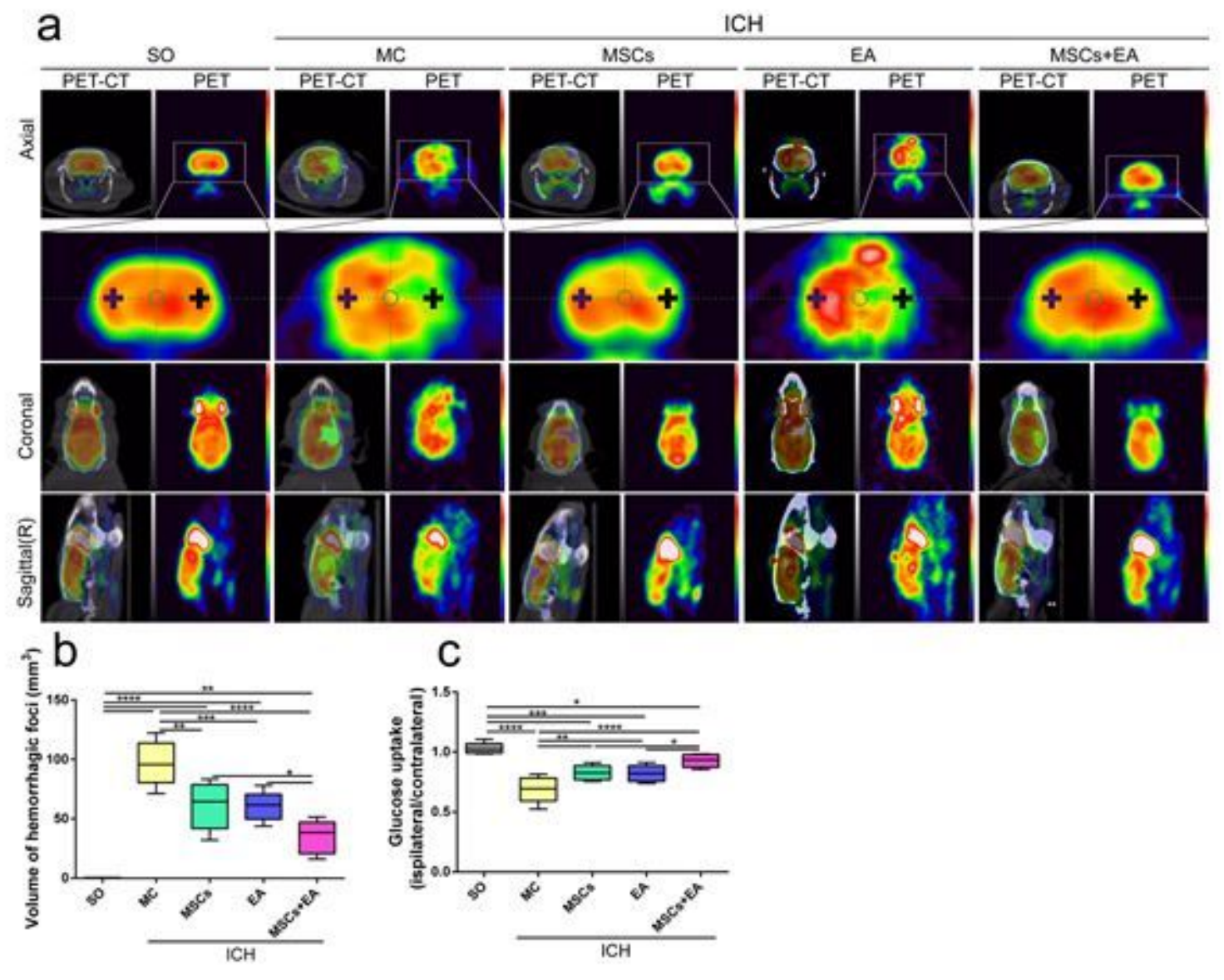

Figure 3

Combined therapy reduce the volume of hemorrhagic foci and increased the level of glucose uptake. a PET-CT images of the rat brains in each group. First, third and fourth rows show axial, coronal and right sagittal images respectively, and the shadow represents the hemorrhagic focus. Second row shows higher magnification views of the boxed areas in first row, and pluses represent the checkpoints (3.4 mm3 per point) of glucose uptake. b-c The quantitative analysis of the volume of hemorrhage focus (b) and glucose uptake quantitative analysis in the peripheral area of hemorrhagic foci (c) via PET-CT scan ( $n=5$

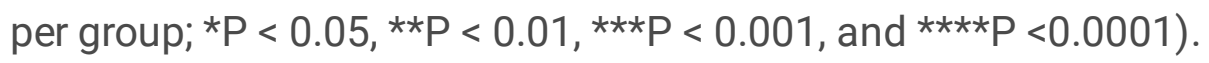



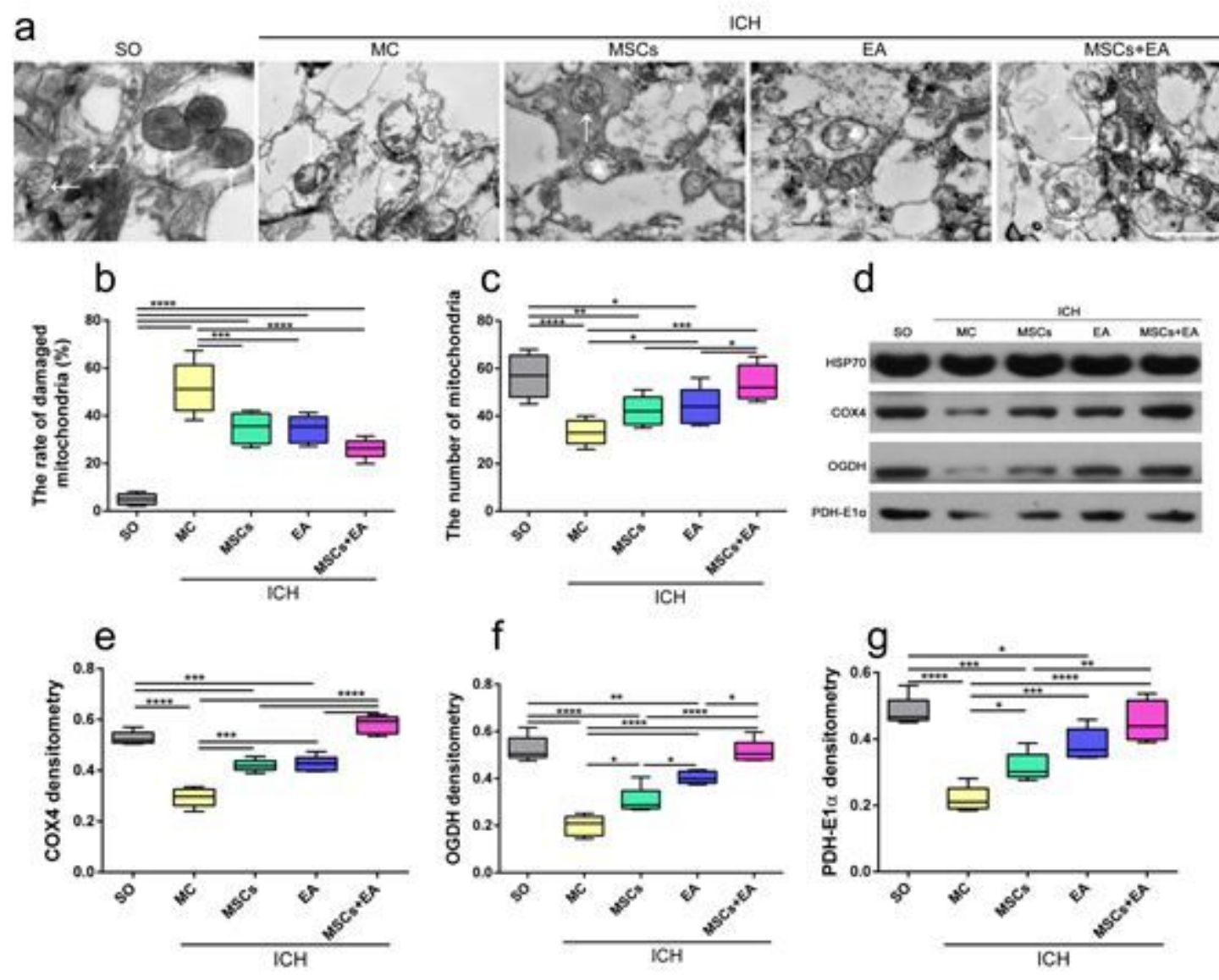

\section{Figure 4}

Combined therapy improve mitochondrial quality in rat brain with $\mathrm{ICH}$. a Electron photomicrographs of the peripheral area of hemorrhagic foci in each group. White arrow: intact mitochondria; Black arrow: part of mitochondrial cristae fracture; White triangle: part of mitochondrial vacuolization (Scale bar, $1 \mu \mathrm{m}$ ). b-c The rates of damaged mitochondria (b) and the number of mitochondria (c) in different groups $(n=4$ per group; $* P<0.05, * \star P<0.01,{ }^{\star} * \star P<0.001$, and $\left.* \star \star \star P<0.0001\right)$. (d) The expressions of COX4, OGDH and $\mathrm{PDH}-\mathrm{E} 1 \mathrm{a}$ in peripheral region of hematoma detected by Western blotting. e-g The relative expressions of COX4, OGDH and PDH-E1a proteins in different groups ( $n=4$ per group; $* P<0.05, \star \star P<0.01, * \star * P<0.001$, and $* \star \star * P<0.0001)$. 


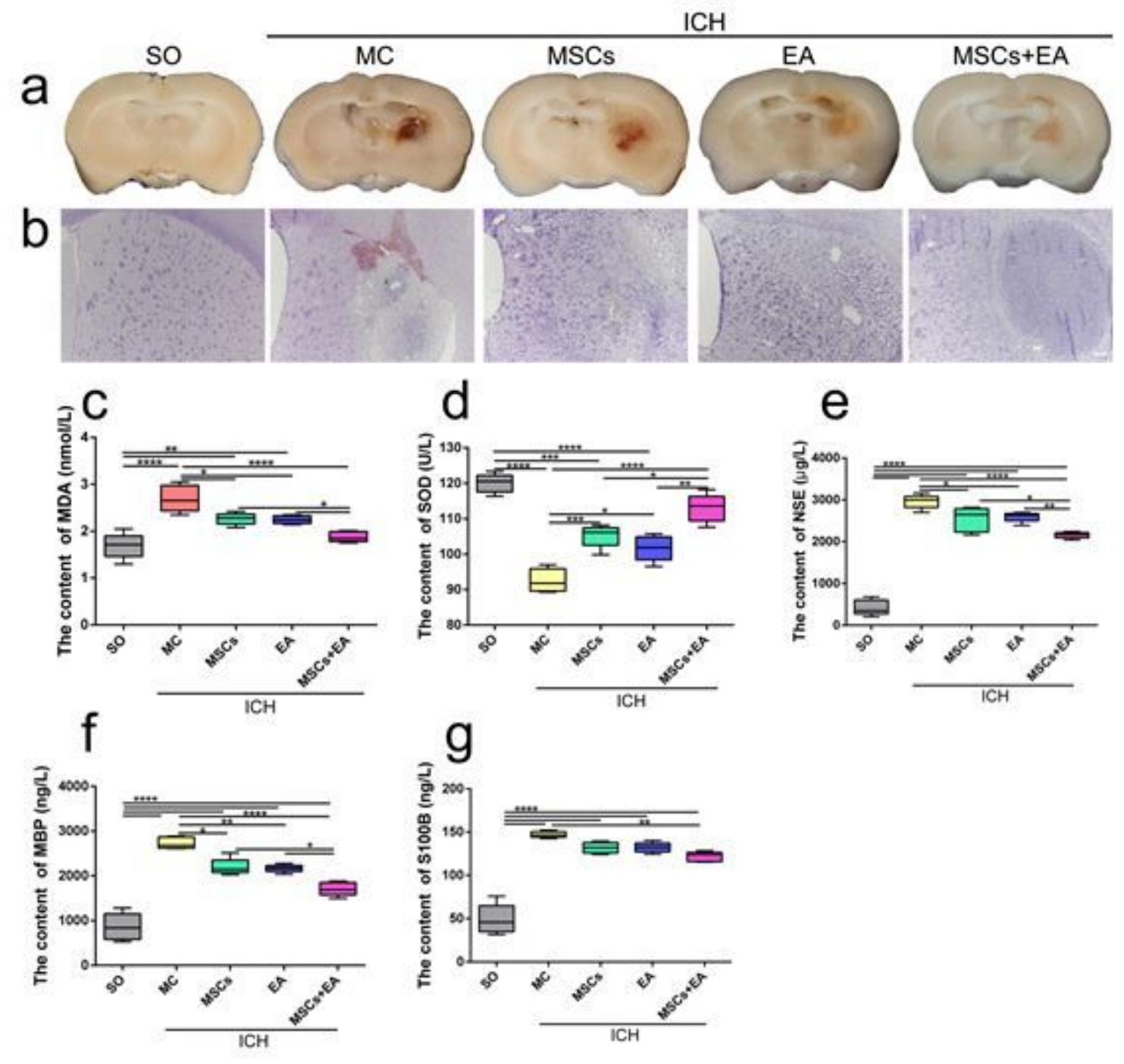

Figure 5

Brain tissue structure and the contents of MDA, SOD, NSE, MBP and S100B in serums/plasma. a Representative images of hematoma in $\mathrm{ICH}$ rats show reduced degree of brain tissue injury after treatment. b Representative brain sections stained with $\mathrm{H} \& \mathrm{E}$ obtained in $\mathrm{ICH}$ rats after treatment. The lesion area was mainly present in the striatum (Scale bars, $500 \mu \mathrm{m}$ ). c-g The content of MDA (c), SOD (d), NSE (e), MBP (f), S100B (g) in serums/plasma in different groups $\left(n=5\right.$ per group; ${ }^{*} P<0.05,{ }^{\star *} P<0.01$, $\star \star \star \mathrm{P}<0.001$, and $\left.{ }^{\star * \star *} \mathrm{P}<0.0001\right)$. 

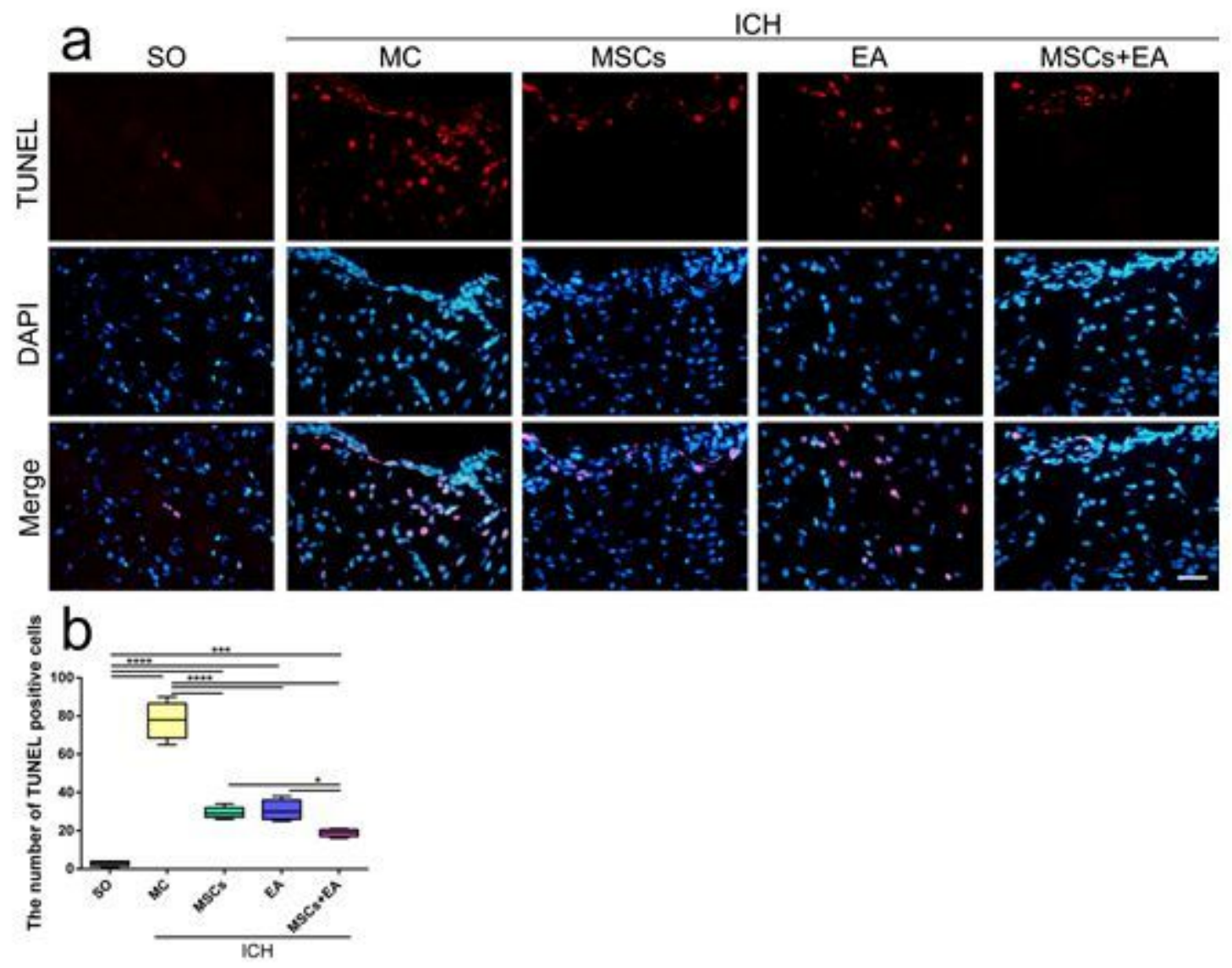

Figure 6

Apoptotic cell detected with TUNEL staining. a Section stained with TUNEL (red) and DAPI (blue) (Scale bar, $100 \mu \mathrm{m})$. $b$ The number of TUNEL-positive cells in different groups ( $n=5$ per group; ${ }^{\star} P<0.05$, $* \star \star P<$ 0.001 , and $* \star \star * P<0.0001)$. 

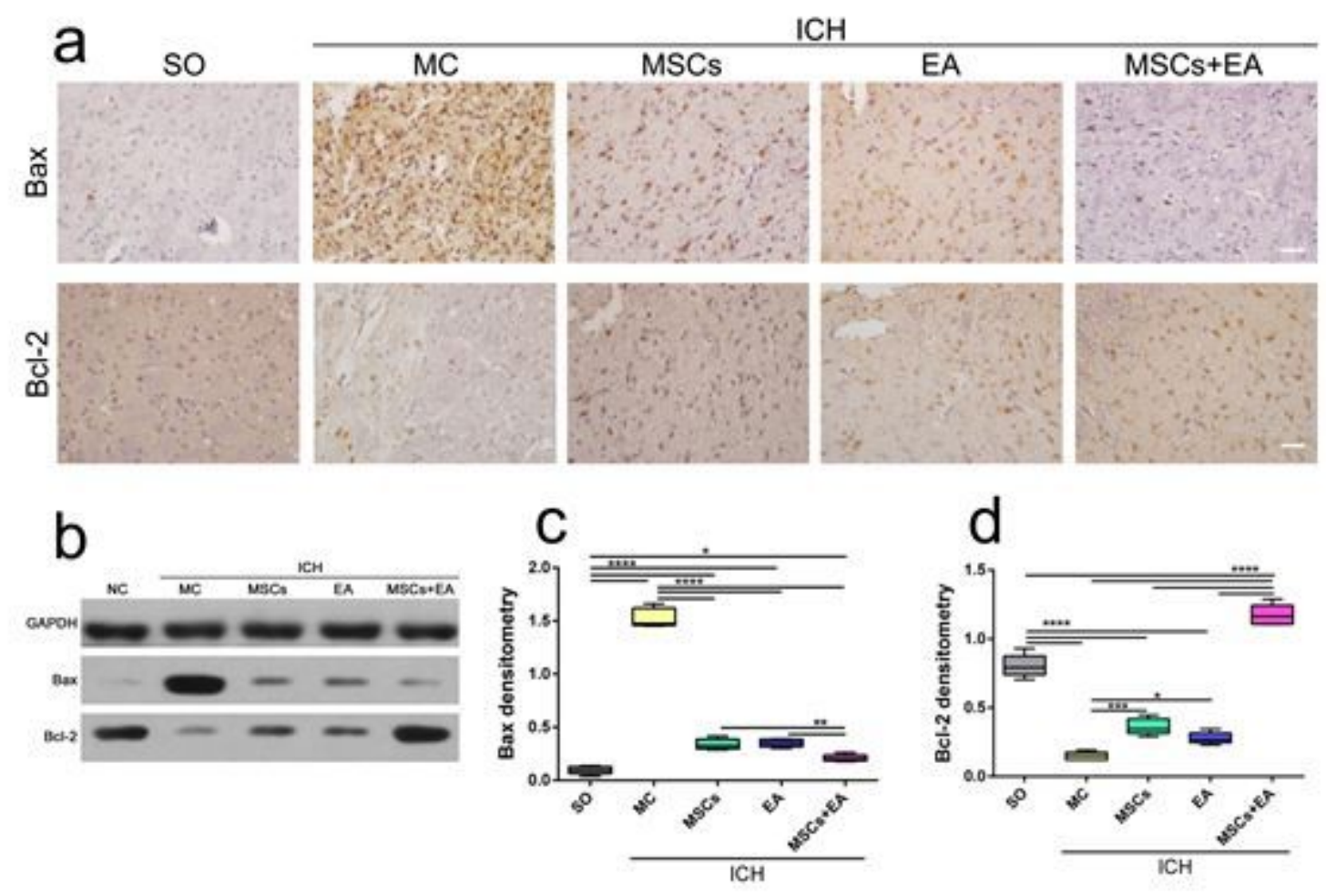

Figure 7

The expressions of apoptotic-related proteins in different groups. a Images of Bax and Bcl-2 immunohistochemistry in ipsilateral striatums of rats (Scale bar, $100 \mu \mathrm{m})$. b The protein expression levels of Bax and Bcl-2 were determined by western blotting. c-d Quantitative analyses of the relative expression levels of $\mathrm{Bax}(\mathrm{c})$ and $\mathrm{Bcl}-2(\mathrm{~d})$ proteins $\left(\mathrm{n}=5\right.$ per group; ${ }^{*} \mathrm{P}<0.05$, $* \star \mathrm{P}<0.01,{ }^{\star \star *} \mathrm{P}<0.001$, and ${ }^{\star \star \star \star *} \mathrm{P}$ $<0.0001)$. 

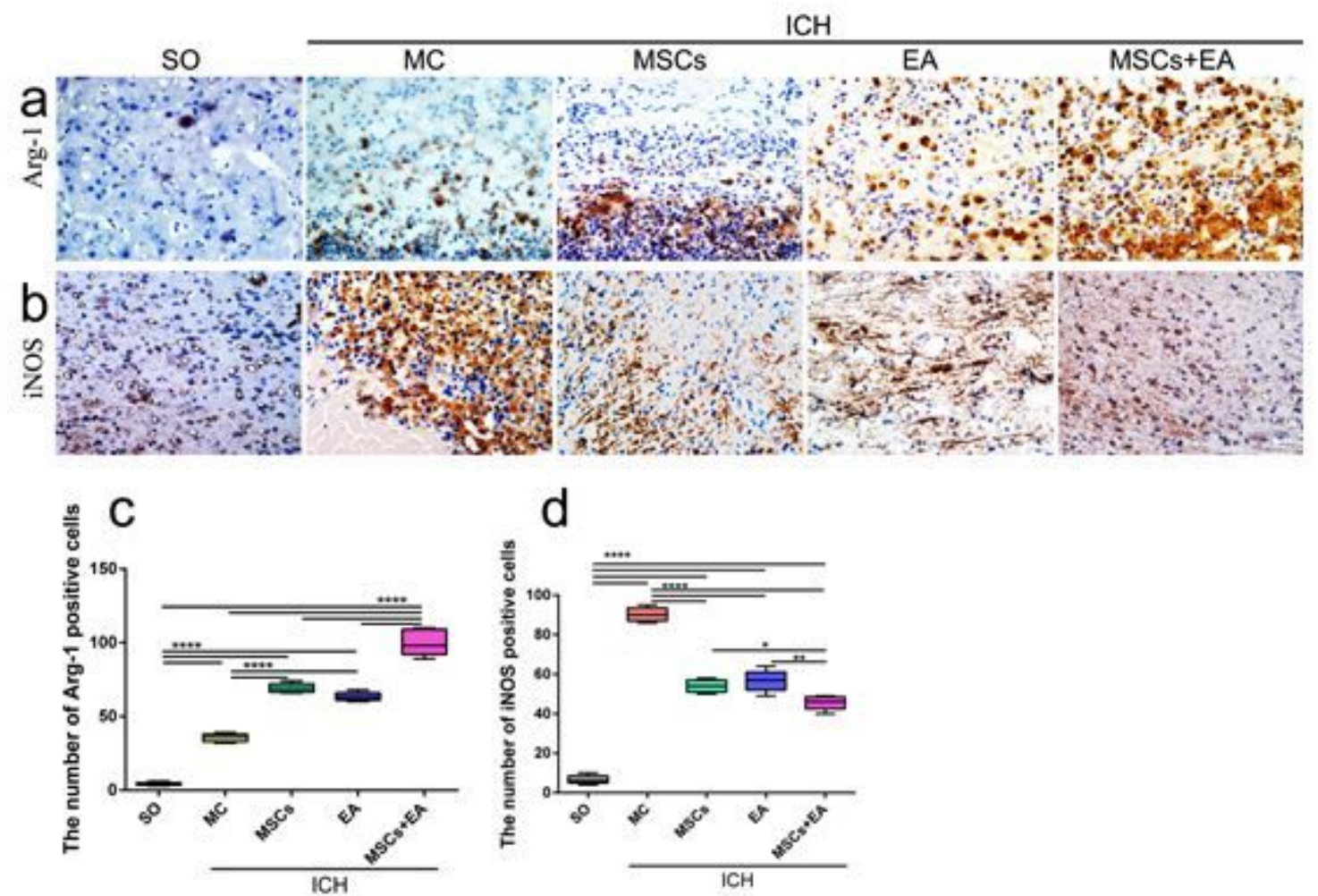

Figure 8

The expressions of microglia-related proteins in different groups. a-b Images of Arg-1 (a) and iNOS (b)

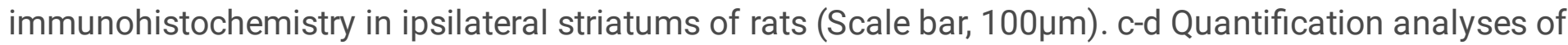
Arg-1 (c) and iNOS (d) postive cells ( $n=5$ per group; $* P<0.05,{ }^{\star *} P<0.01, * \star \star P<0.001$, and ${ }^{\star \star \star \star} P$ $<0.0001)$.

\section{Supplementary Files}

This is a list of supplementary files associated with this preprint. Click to download.

- SupplementaryFig.1.doc 